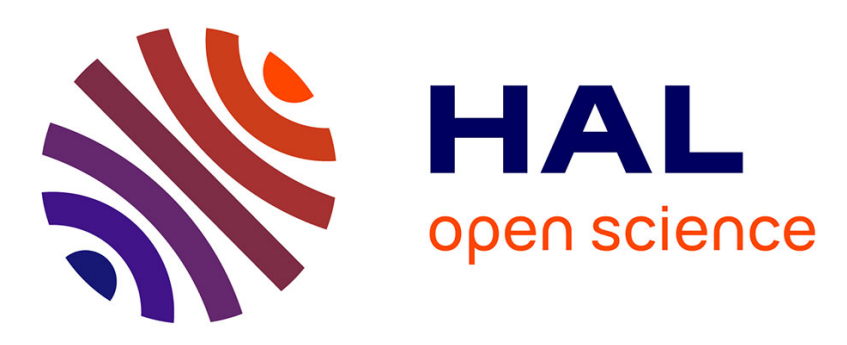

\title{
Single-Molecule Magnet Behavior in Dy 3+ Half-Sandwich Complexes Based on Ene-Diamido and Cp* Ligands
}

Jérome Long, Aleksei Tolpygin, Anton Cherkasov, Konstantin A. Lyssenko, Yannick Guari, Joulia Larionova, Alexander A. Trifonov

\section{To cite this version:}

Jérome Long, Aleksei Tolpygin, Anton Cherkasov, Konstantin A. Lyssenko, Yannick Guari, et al.. Single-Molecule Magnet Behavior in Dy 3+ Half-Sandwich Complexes Based on Ene-Diamido and Cp* Ligands. Organometallics, 2019, 38 (4), pp.748-752. 10.1021/acs.organomet.8b00901 . hal02047664

\section{HAL Id: hal-02047664 \\ https://hal.science/hal-02047664}

Submitted on 26 Nov 2020

HAL is a multi-disciplinary open access archive for the deposit and dissemination of scientific research documents, whether they are published or not. The documents may come from teaching and research institutions in France or abroad, or from public or private research centers.
L'archive ouverte pluridisciplinaire HAL, est destinée au dépôt et à la diffusion de documents scientifiques de niveau recherche, publiés ou non, émanant des établissements d'enseignement et de recherche français ou étrangers, des laboratoires publics ou privés. 


\title{
Single-Molecule Magnet Behavior in $\mathrm{Dy}^{3+}$ Half-Sandwich Complexes based on ene-diamido and $\mathrm{Cp} *$ Ligands.
}

\author{
Jérôme Long*, ${ }^{\text {a }}$ Aleksei O. Tolpygin, ${ }^{\mathrm{b}}$ Anton V. Cherkasov, ${ }^{\mathrm{b}}$ Konstantin A. Lyssenko, ${ }^{\mathrm{c}}$ Yannick Guari, ${ }^{\mathrm{a}}$ \\ Joulia Larionova, ${ }^{\mathrm{a}}$ Alexander A. Trifonov*b,c
}

\author{
${ }^{a}$ Institut Charles Gerhardt, Equipe Ingénierie Moléculaire et Nano-Objets, Université de Montpellier, ENSCM, CNRS. Place \\ Eugène Bataillon, 34095 (France). \\ ${ }^{\mathrm{b}}$ Institute of Organometallic Chemistry of Russian Academy of Sciences, 49 Tropinina str., GSP-445, 630950, Nizhny Nov- \\ gorod (Russia). \\ ${ }^{\mathrm{c}}$ Institute of Organoelement Compounds of Russian Academy of Sciences, 28 Vavilova str., 119334 , Moscow (Russia).
}

\begin{abstract}
We report in this communication the synthesis, structure and magnetic investigations of two new half-sandwich complexes [Dy(DAD)Cp*(THF)] (1) and $\left[\mathrm{Li}(\mathrm{THF})_{3}\right][\mathrm{Dy}(\mathrm{DAD}) \mathrm{Cp} * \mathrm{Cl}](\mathbf{2})\left(\mathrm{Cp}^{*}=\mathrm{C}_{5} \mathrm{Me}_{5}, \mathrm{DAD}=[2,6-\right.$ $\left.\mathrm{iPr}_{2} \mathrm{C}_{6} \mathrm{H}_{3} \mathrm{~N}-\mathrm{CMe}=\mathrm{CMe}-\mathrm{NC}_{6} \mathrm{H}_{3} \mathrm{iPr} 2-2,6\right)$. Both compounds exhibit zero-field SMM behavior but distinct relaxation dynamics originating from difference in the arrangement of $\mathrm{Cp}^{*}$ and $\mathrm{DAD}$ ligands. The anisotropic barrier for $\mathbf{1}$ is found one order of magnitude greater than for $\mathbf{2}$.
\end{abstract}

Coordination complexes exhibiting slow relaxation of their magnetization associated with magnetic bistability show tremendous potentialities for information storage or spin-based computing. ${ }^{1}$ Since the report of such effect more than two decades ago, ${ }^{2}$ the chemical design and resulting properties of such SingleMolecule Magnets (SMMs) have been greatly enhanced by taking advantage of the fascinating properties of lanthanide ions. ${ }^{\text {lb, } 3}$ In $4 f$ complexes, the appropriate combination between a specific lanthanide ion and surrounding ligands generates a crystal-field that may allow the appearance of an anisotropic barrier, $\Delta$, that separates two opposite directions of the magnetic moment $\left( \pm m_{\mathrm{J}}\right)$. Naturally, increasing the crystal-field splitting should result in larger anisotropic barriers and blocking temperatures (which could be the temperature at which or relaxation time is equal to $100 \mathrm{~s}$ or alternatively as the highest temperature at which an hystereis loop is observed). ${ }^{4}$ Such systems with largely separated $\pm m_{\mathrm{J}}$ states could be engineered based on simple electrostatic considerations that exploit the optimum stabilization the electronic density of the $4 f$ ions. Thus, lanthanide ions such as $\mathrm{Dy}^{3+}$ exhibiting oblate electronic density are efficiently stabilized by axial crystal-field that maximizes the splitting of the $m_{\mathrm{J}}$ levels and stabilizes the highest $m_{\mathrm{J}}= \pm 15 / 2$ states, while minimizing the Quantum Tunneling of the Magnetization (QTM). However, such scenario is frequently altered by the existence of additional spinlattice relaxation processes (Raman and direct) which create underbarrier relaxation paths. ${ }^{1 \mathrm{~b}, 3,5}$

One possible strategy to obtain large axial crystal-field relies on the use of coordination ${ }^{6}$ or organometallic chemistry ligands ${ }^{7}$ that reduce the lanthanide coordination number while simultaneously

affording an efficient stabilization of the $4 f$ electronic density. In this regards, major advances have been recently achieved with $\mathrm{Dy}^{3+}$ metallocenium complex based on cyclopentadienyl $\left(\mathrm{Cp}^{\mathrm{R}}\right)$ ligands ${ }^{8}$ that show exceptional magnetic hysteresis features that could overcome liquid nitrogen's temperature. ${ }^{9}$ In this last example, the heteroleptic sandwich complex $\left[\mathrm{Dy}\left(\mathrm{Cp}^{\mathrm{iPr} 5}\right)\left(\mathrm{Cp} \mathrm{p}^{*}\right)\right]\left[\mathrm{B}\left(\mathrm{C}_{6} \mathrm{~F}_{5}\right)_{4}\right]$ was found to exhibit large anisotropy thanks to a synergy between short Dy-Cp*/iPr5 distances and large $\mathrm{Cp}-\mathrm{Dy}-\mathrm{Cp}$ angle. Additionally, these impressive relaxation dynamics appear to be not solely related to the targeted coordination environment but also to the reduced molecular vibrations (metalligands vibrational modes) imposed by the rigid Cp ligands. ${ }^{5,8 a}, 8 \mathrm{~b}$, ${ }^{9}$ It appears therefore essential to gain deeper understanding on the parameters affecting such spin-phonon coupling.

In this sense, we have recently reported the use of doubly reduced diazabutadiene ligands for the design of lanthanide SMMs. ${ }^{10}$ These anionic ligands, acting as both, $n$ and $\pi$-electron donors, benefit from a large steric and electronic tunability that could be taken as an advantage to create highly axial crystal-field. In our previous studies, the homoleptic $\mathrm{Li}(\mathrm{DME})_{3}\left[\mathrm{Dy}(\mathrm{DAD})_{2}\right]$ complex $\left(\mathrm{DAD}=\left[2,6-\mathrm{iPr}_{2} \mathrm{C}_{6} \mathrm{H}_{3} \mathrm{~N}-\mathrm{CH}=\mathrm{CH}-\mathrm{NC}_{6} \mathrm{H}_{3} \mathrm{iPr}_{2}-2,6\right]\right)$ exhibit a genuine SMM behaviour. ${ }^{10 \mathrm{~b}}$ Yet, despite a significant crystal-field splitting generated by these ligands, Raman relaxation was found to dominate the relaxation dynamics. Aiming at reducing this spin-phonon coupling while increasing the magnetic anisotropy, we propose here to associate bulky DAD-type ligands, that are known to generate short $\mathrm{Dy}-\mathrm{N}$ distances, with rigid $\mathrm{Cp}^{*}$ moiety in order to design heteroleptic half-sandwich dysprosium complexes.

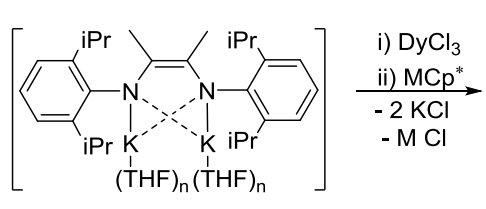

Scheme 1: Synthesis of 1 and 2.

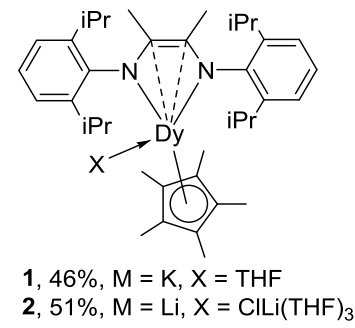

1, 46\%,M $=K, X=T H F$
$2,51 \%, M=L i, X=C I L i(T H F)_{3}$ 
The synthetic strategy to design the targeted heteroleptic halfsandwich-type complexes [Dy(DAD) $\mathrm{Cp}^{*}$ ] relies on the cascade of reactions of anhydrous $\mathrm{DyCl}_{3}$ with $\left[\mathrm{DADK}_{2}(\mathrm{THF})_{n}\right]$ and alkali metal cyclopentadienide $\mathrm{MCp}^{*}(\mathrm{M}=\mathrm{Li}, \mathrm{K})$ (Scheme 1). Using $\mathrm{KCp}^{*}$ leads to the formation of a salt-free complex [Dy(DAD)Cp*(THF)] (1), while in the case of $\mathrm{LiCp}^{*}$, atecomplex $\left[\mathrm{Li}(\mathrm{THF})_{3}\left(\mu^{2}-\mathrm{Cl}\right) \mathrm{Dy}(\mathrm{DAD}) \mathrm{Cp}^{*}\right]$ (2) was isolated (see ESI for details).

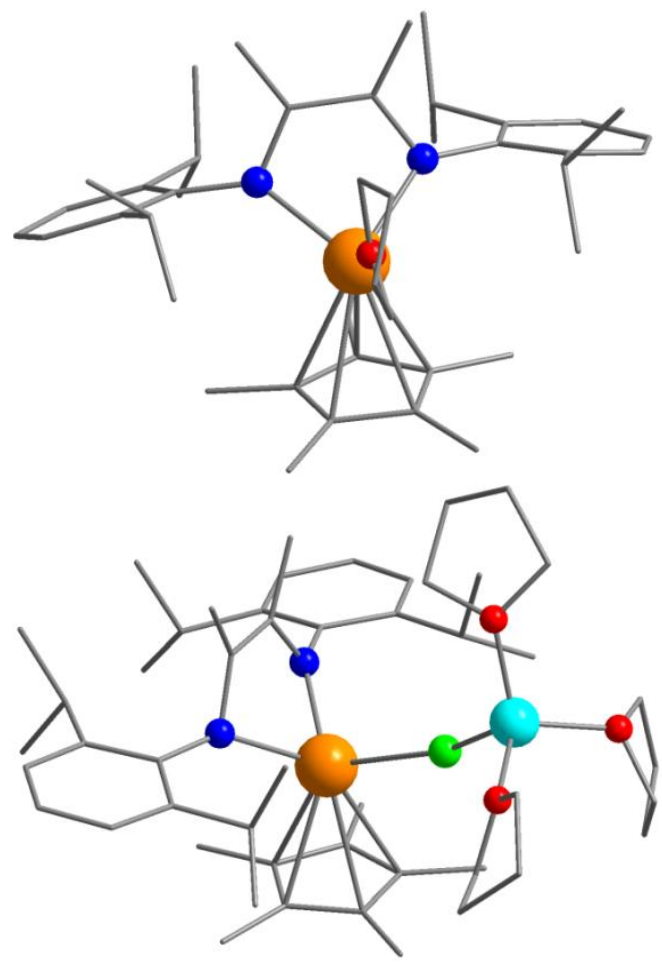

Fig. 1. Structure of 1 (top) and $\mathbf{2}$ (bottom). Color code: orange, Dy; red, O; grey, C; green, $\mathrm{Cl}$; light blue, Li. Hydrogen atoms have been omitted for clarity.

The X-ray diffraction studies indicate that both compounds crystallize in the $P 2_{1} / c$ space group with a unique complex within the asymmetric unit (Table S1). Compound $\mathbf{1}$ is isostructural to the ytterbium complex we recently obtained. ${ }^{11}$ The coordination environments of the $\mathrm{Dy}^{3+}$ in $\mathbf{1}$ and $\mathbf{2}$ are composed of one $\mathrm{Cp}^{*}$ ligand, one dianionic $2 \sigma: \eta^{2}$ ene-diamido $\mathrm{DAD}^{2-}$ ligand and one coordinated THF molecule (for $\mathbf{1}$ ) or $\mu^{2}-\mathrm{ClLi}(\mathrm{THF})_{3}$ fragment (for 2). The $\mathrm{Dy}-\mathrm{C}_{\mathrm{Cp}}$ bond lengths in 1 are ranging from 2.612(2) to 2.727(1) $\AA$, the Dy-C $\mathrm{p}_{\text {Centr }}$ distance is of 2.391(2) $\AA$ (Table S2). The Dy-N bond lengths are slightly different and equal to 2.189(2) and 2.202(2) $\AA$. With respect to 1 , the Dy-C $p_{C e n t r}$ distance in 2 (2.367(2) $\AA$ ) is slightly shorter, while one Dy-N bond lengths is longer (2.198(2) and 2.205(2) A). The Dy-N bond lengths in $\mathbf{1}$ and $\mathbf{2}$ are noticeably shorter than the related values measured for eight-coordinate $\mathrm{Dy}^{3+}$ complexes and correspond to covalent Dy-N bonds. ${ }^{12}$ The short distances between the $\mathrm{Dy}^{3+}$ ions and the carbon atoms of the NCCN moiety in 1 (2.837(2), $2.845(2) \AA)$ and 2 (2.764(2), 2.769(2) $\AA$ ) are indicative of $\eta^{2}$ coordination of the $\mathrm{C}=\mathrm{C}$ bonds to the $\mathrm{Dy}^{3+}$ ion. However, these distances are longer than in the previously reported $\left[\mathrm{Li}(\mathrm{DME})_{3}\right]\left[\mathrm{Dy}(\mathrm{DAD})_{2}\right] \quad(2.672(3)-2.712(5) \AA) .^{10 \mathrm{~b}}$ The Dy-O distance in $\mathbf{1}$ is equal to $2.362(2) \AA$. In 2 , the $\mathrm{Cl}^{-}$ligand $\mu^{2}$-bridges $\left[\mathrm{Li}(\mathrm{THF})_{3}\right]^{+}$and $\mathrm{Dy}^{3+}$ ions. The Dy-Cl distance is 2.6403(6) $\AA$ and the $\mathrm{Li}-\mathrm{Cl}$ one is of 2.339(4) $\AA$. Taking into account the two centroids defined by the $\mathrm{DAD}^{2-}(\mathrm{NCCN})$ and $\mathrm{Cp}^{*}$ ligands, bite angles of $142.0(2)^{\circ}$ and $139.6(2)^{\circ}$ are found for 1 and 2 respectively. The shortest intermolecular $\mathrm{Dy}^{3+}-\mathrm{Dy}^{3+}$ distance measured in 1 (9.543(2) $\AA$ ) proved to be noticeably shorter compared to that in 2 (11.413(2) ̊) (Fig. S1).

The magnetic properties of $\mathbf{1}$ and $\mathbf{2}$ were investigated in both, static and dynamic modes. The detailed dc measurements could be found in the ESI and reveal differences that may originate from dissimilar crystal-field splitting.

The occurrence of slow relaxation of the magnetization was investigated by alternating current (ac) measurements. Under a zero-dc field, the compounds exhibit a clear frequency dependence in the in-phase $\left(\chi^{\prime}\right)$ and in the out-of-phase $\left(\chi^{\prime \prime}\right)$ components of the magnetic susceptibility (Fig. 2, Fig. S4-S5) indicating a SMM behavior. While for $\mathbf{1}$ a maximum could be discerned, 2 exhibits a very broad signal without a clear maximum of $\chi$ ". The Cole-Cole plots (Fig. S6) reveal the presence of two relaxation processes for $\mathbf{1}$. These data could be fitted with the sum of two modified Debye functions ${ }^{13}$ for 1 (Table S3) leading to large values (i.e. 0.6) of the $\alpha$ parameter at low temperature for the main relaxation process but such treatment yields to unrealistic fitting parameters for 2 .

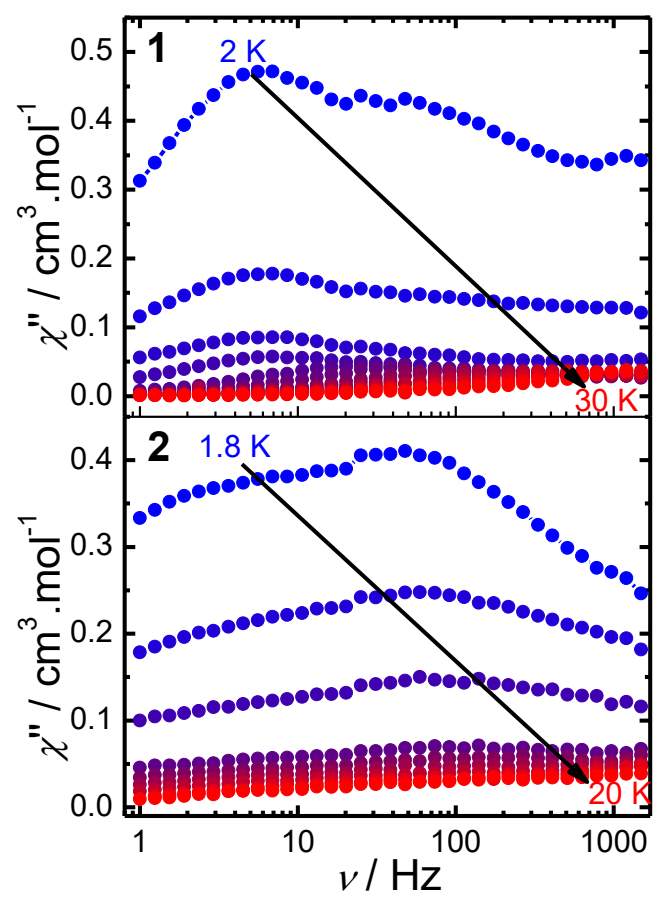

Fig. 2. Frequency dependence of the out-of phase ( $\left.\chi^{\prime \prime}\right)$ susceptibilities for $\mathbf{1}$ and $\mathbf{2}$ under a zero dc-field.

Insights into the dynamics of the relaxation of the magnetization could be obtained from the temperature dependence of the relaxation time, $\tau$. The broad maximum for 2 prevent extracting relevant values of $\tau$. The $\ln \tau v s . T^{-1}$ plot for 1 related to the main relaxation process deviates from the linearity before becoming temperature independent at low temperature, indicating the presence of QTM (Fig. 3, Fig. S7). Consequently, the overall data range could be modeled using the following equation: $\tau^{-1}=$ $\tau_{0}^{-1} \exp (-\Delta / k T)+C T^{n}+\tau^{-1}$ QTM (Eq. 1). ${ }^{14}$ The first term accounts for a thermally activated process, while the second and third ones stand for two-phonon Raman and QTM, respectively. In order to avoid over-parameterization, $n$ was fixed to different values until getting the best fitting coefficient. The obtained fit parameters (Table 1) point out that a relaxation involving these three different processes. The low value of the $n$ exponent as observed in others

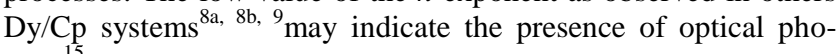
nons $^{15}$ 
Table 1: Fit parameters of the temperature dependence of the relaxation time for $\mathbf{1}$ and $\mathbf{2}$.

\begin{tabular}{|c|c|c|c|c|c|}
\hline Compound & $\begin{array}{c}\Delta \\
\left(\mathrm{cm}^{-1}\right)\end{array}$ & $\tau_{0}(s)$ & $n^{*}$ & $\begin{array}{c}C \\
\left(\mathrm{~s}^{-1} \cdot \mathrm{K}^{-m}\right)\end{array}$ & $\begin{array}{c}A \\
\left(\mathrm{~s}^{-1} \cdot \mathrm{K}^{-1}\right)\end{array}$ \\
\hline $\mathbf{1}(0 \mathrm{Oe})$ & $254 \pm 17$ & $\begin{array}{c}(6 \pm 5) \times \\
10^{-10}\end{array}$ & 3 & $0.008 \pm 0.005$ & - \\
\hline $\mathbf{1}(2000 \mathrm{Oe})$ & $206 \pm 10$ & $\begin{array}{c}(10 \pm 4) \times \\
10^{-9}\end{array}$ & 3 & $0.007 \pm 0.003$ & - \\
\hline $\mathbf{2}(1000 \mathrm{Oe})$ & $20 \pm 4$ & $(5 \pm 3) \times 10^{-9}$ & - & - & $281 \pm 139$ \\
\hline
\end{tabular}

*fixed parameter

In order to reduce the observed QTM, the field dependence of the ac susceptibilities was studied. An increase of the relaxation time is observed with optimum fields found at 2000 and $1000 \mathrm{Oe}$ for $1(15 \mathrm{~K})$ and $\mathbf{2}(2 \mathrm{~K})$, respectively (Fig. S8). The field dependence of $\tau$ could be modeled with the equation $\tau^{-1}=D H^{4} T+$ $B_{1} /\left(1+B_{2} H^{2}\right)+K($ Eq. 2$)$, for which the first term accounts for the direct process (for Kramers-ion), the second one for the QTM and the $K$ constant accounts for the field-independent Raman and thermally activated processes (Fig. S9, Table S4). The frequency dependence of the ac susceptibilities measured under these dc fields confirms the shortcut of the QTM. While a broad maximum of $\chi^{\prime \prime}$ could be still observed for $\mathbf{1}$, applying a dc field totally modifies the frequency dependence of $\chi$ " for 2 (Fig. S10). Thus, although a plateau is observed at low frequencies (also confirmed by the Cole-Cole plots, Fig. S11, Table S6), a clear maximum could be now discerned allowing the extraction of the relaxation time. The temperature dependence of the relaxation time (Fig. 3) for both complexes could be fitted with: $\tau^{-1}=\tau_{0}{ }^{-1} \exp (-\Delta / k T)+$ $C T^{n}+A T$ (Eq. 3) (Fig. 3, Fig. S7, Table 1) in which the third term accounts for the direct process. $\Delta$ is found one order of magnitude lower for $\mathbf{2}$ with respect to $\mathbf{1}$ confirming an important difference in the crystal-field spitting as previously evidenced from the dc measurements. Moreover, although no direct process could be evidenced for $\mathbf{1}$, it contributes greatly to the overall relaxation for 2, while the Raman process is found inoperative;

The magnetic analysis indicates a dramatic variation in the dynamic of slow relaxation of the magnetization for $\mathbf{1}$ and $\mathbf{2}$ despite a closely related structure. To get further insights, magnetostructural correlations could be achieved by evaluation of the orientation of the anisotropic axes of the ground Kramers doublet using the MAGELLAN ${ }^{16}$ software based on electrostatic considerations. As expected, the orientation of the anisotropic axes for both complexes are mainly imposed by both, $\mathrm{Cp}^{*}$ and DAD-Me ligands (Fig. S12). Hence, a deviation of less than $15^{\circ}$ with the anisotropic axis is observed between the centroids of DAD-Me and $\mathrm{Cp}^{*}$ ligands (Table S7). Moreover, the THF or chloride in $\mathbf{1}$ and 2, respectively, define a mean angle close to $90^{\circ}$ with the anisotropic axis, inducing a transverse component that explains the QTM. Surprisingly, substitution of a THF by a negatively charged chloride does not induce a significant tilt of the anisotropic axis for 2 . This could be imputed to the rather long $\mathrm{Dy}-\mathrm{Cl}$ distance of $2.640 \AA$ to compare with the shorter Dy-O one of $2.363 \AA$, counterbalancing the effect of the chloride negative charge. On the other hand, 1 exhibits the shortest $\mathrm{Dy}^{3+-} \mathrm{Dy}^{3+}$ distance. It should therefore exhibit the highest tunneling rate caused by dipolar interactions which is not experimentally observed.

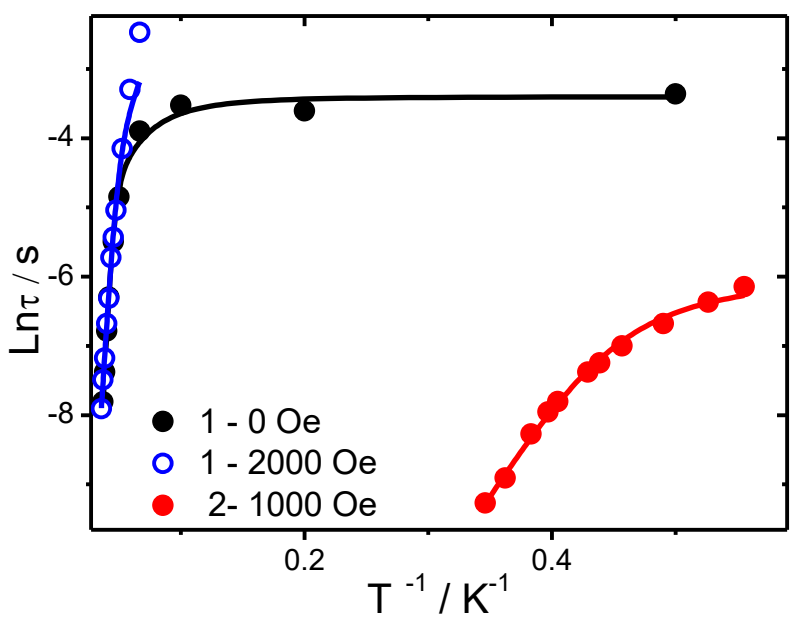

Fig. 3. Temperature dependence of $\tau$, for $\mathbf{1}$ and $\mathbf{2}$. The solid lines correspond to the fit with Eq. 1or Eq. 3.

Hence, the observed differences in the magnetic properties may be rather explained by subtle differences in the arrangement of $\mathrm{DAD}-\mathrm{Me}$ and $\mathrm{Cp}^{*}$ ligands. Recent studies on dysprosium metallocene complexes $\left[\mathrm{Dy}\left(\mathrm{Cp}^{\mathrm{R}}\right)_{2}\right]^{+}$clearly point out two critical parameters that affect the magnetic axiality in these systems: the $\mathrm{Cp}-\mathrm{Dy}-\mathrm{Cp}$ angle and Dy-C distances. Maximizing the anisotropy requires achieving large bite angles, while shortening the Dy-C bonds. ${ }^{17-20}$ Despite the fact that the Dy-C are found slightly shorter in $\mathbf{2}$, the greater bite angle Cp*-Dy-DAD associated with the reduced Dy-N distances for $\mathbf{1}$ may explain its larger crystal-field splitting and greater anisotropic barrier. Such dominant influence of the DAD ligand is also in line with its two-fold greater negative charge carried in comparison with $\mathrm{Cp}^{*}$.

Furthermore, the magnetic properties of $\mathbf{1}$ may be favorably compared with those obtained in our previously reported homoleptic complex $\left[\mathrm{Li}(\mathrm{DME})_{3}\right]\left[\mathrm{Ln}(\mathrm{DAD})_{2}\right] .{ }^{10 \mathrm{~b}}$ In this latter, the DAD-Dy-DAD angle was closer to the linearity $\left(172^{\circ}\right)$, but significantly larger Dy-N distances of 2.221-2.246 $\AA$ were found. In addition, the magnetization was found to mainly relax through a Raman process. Consequently, incorporation of rigid $\mathrm{Cp}^{*}$ moieties in association with DAD ligands permits to increase the axiality while reducing the Raman relaxation.

In summary, we have reported in this article two different heteroleptic $\mathrm{Dy}^{3+}$ complexes based on DAD and $\mathrm{Cp} *$ ligands. Although they differ by the nature of an additional coordinated species (THF vs. $\mathrm{Cl}^{-}$), both compounds exhibit distinct slow relaxation of the magnetization dynamics caused by slight changes in the Dy-N distances and $\mathrm{Cp}^{*}$-Dy-DAD angles. Thanks to the great tunability of both, DAD and Cp ligands, extension to other heteroleptic complexes exhibiting shorter Dy-N distances and greater bite angles may be viewed as a promising route to enhance the magnetic relaxation properties in lanthanide SMM.

\section{ASSOCIATED CONTENT}

\section{Supporting Information}

The Supporting Information is available free of charge on the ACS Publications website. Experimental procedures, additional structural and magnetic data could be found in the PDF.

\section{AUTHOR INFORMATION}

\section{Corresponding Author}

*E-mail: jerome.long@umontpellier.fr 
*E-mail: trif@iomc.ras.ru

\section{Author Contributions}

$\$$ All the authors contributed equally.

\section{Notes}

The authors declare no competing financial interests.

\section{ACKNOWLEDGMENT}

The financial support of the Russian Science Foundation is highly acknowledged (Project № 17-73-30036). The X-ray study of $\mathbf{1}$ has been carried out in the framework of the Russian state assignment (Theme № 44.2, Reg. № AAAA-A16-116122110053-1) using the equipment of The Analytical Center of IOMC RAS. The French authors thank the University of Montpellier, CNRS and PAC of ICGM.

\section{REFERENCES}

(1) (a) Luzon, J.; Sessoli, R., Lanthanides in molecular magnetism: so fascinating, so challenging. Dalton Trans. 2012, 41 (44), 13556-13567; (b) Woodruff, D. N.; Winpenny, R. E. P.; Layfield, R. A., Lanthanide single-molecule magnets. Chem. Rev. 2013, 113 (7), 5110-5148; (c) Troiani, F.; Affronte, M., Molecular spins for quantum information technologies. Chem. Soc. Rev. 2011, 40 (6), 3119-3129; (d) Bogani, L.; Wernsdorfer, W., Molecular spintronics using single-molecule magnets. Nat. Mater. 2008, 7 (3), 179-186.

(2) (a) Sessoli, R.; Tsai, H. L.; Schake, A. R.; Wang, S.; Vincent, J. B.; Folting, K.; Gatteschi, D.; Christou, G.; Hendrickson, D. N., High-spin molecules: [Mn12O12(O2CR)16(H2O)4]. J. Am. Chem. Soc. 1993, 115 (5), 1804-1816; (b) Sessoli, R.; Gatteschi, D.; Caneschi, A.; Novak, M. A., Magnetic bistability in a metal-ion cluster. Nature 1993, 365, 141.

(3) (a) Tang, J.; Zhang, P., Lanthanide Single-Ion Molecular Magnets. In Lanthanide Single Molecule Magnets, Springer Berlin Heidelberg: Berlin, Heidelberg, 2015; pp 41-90; (b) Layfield, R. A.; Murugesu, M., Lanthanides and Actinides in Molecular Magnetism. Wiley: 2015; (c) Ungur, L.; Chibotaru, L. F., Strategies toward High-Temperature Lanthanide-Based Single-Molecule Magnets. Inorg. Chem. 2016, 55 (20), 10043-10056.

(4) Gatteschi, D.; Sessoli, R.; Villain, J., Molecular Nanomagnets. Oxford Univ. Press, New York, 20072006.

(5) Escalera-Moreno, L.; Baldoví, J. J.; Gaita-Ariño, A.; Coronado, E., Spin states, vibrations and spin relaxation in molecular nanomagnets and spin qubits: a critical perspective. Chem. Sci. 2018, 9 (13), 3265-3275.

(6) (a) Gupta, S. K.; Rajeshkumar, T.; Rajaraman, G.; Murugavel, R. An air-stable Dy(iii) single-ion magnet with high anisotropy barrier and blocking temperature. Chem. Sci. 2016, 7 (8), 5181-5191; (b) Chen, Y.-C.; Liu, J.-L.; Ungur, L.; Liu, J.; Li, Q.-W.; Wang, L.-F.; Ni, Z.-P.; Chibotaru, L. F.; Chen, X.-M.; Tong, M.-L., Symmetry-Supported Magnetic Blocking at $20 \mathrm{~K}$ in Pentagonal Bipyramidal Dy(III) Single-Ion Magnets. J. Am. Chem. Soc. 2016, 138 (8), 2829-2837.

(7) (a) Layfield, R. A., Organometallic Single-Molecule Magnets. Organometallics 2014, 33 (5), 1084-1099; (b) Liu, J.; Chen, Y.-C.; Liu, J.L.; Vieru, V.; Ungur, L.; Jia, J.-H.; Chibotaru, L. F.; Lan, Y.; Wernsdorfer, W.; Gao, S.; Chen, X.-M.; Tong, M.-L., A Stable Pentagonal Bipyramidal Dy(III) Single-Ion Magnet with a Record Magnetization Reversal Barrier over 1000 K. J. Am. Chem. Soc. 2016, 138 (16), 54415450; (c) Gregson, M.; Chilton, N. F.; Ariciu, A.-M.; Tuna, F.; Crowe, I. F.; Lewis, W.; Blake, A. J.; Collison, D.; McInnes, E. J. L.; Winpenny, R. E. P.; Liddle, S. T., A monometallic lanthanide bis(methanediide) single molecule magnet with a large energy barrier and complex spin relaxation behaviour. Chem. Sci. 2016, 7 (1), 155-165; (d) Ding, Y.-S.; Chilton, N. F.; Winpenny, R. E. P.; Zheng, Y.-Z., On Approaching the Limit of Molecular Magnetic Anisotropy: A Near-Perfect Pentagonal Bipyramidal Dysprosium(III) Single-Molecule Magnet. Angew. Chem. Int. Edit. 2016, 55 (52), 16071-16074; (e) Meng, Y.-S.; Xu, L.; Xiong, J.; Yuan, Q.; Liu, T.; Wang, B.-W.; Gao, S., Low-Coordinate Single-Ion Magnets by Intercalation of Lanthanides into a Phenol Matrix. Angew. Chem. Int. Edit. 2018, 57 (17), 4673-4676; (f) Day, B. M.; Guo, F.-S.; Layfield, R. A., Cyclopentadienyl Ligands in Lanthanide Single-Molecule Magnets: One Ring To Rule Them All? Acc. Chem. Res. 2018, 51 (8), 1880-1889.

(8) (a) Guo, F.-S.; Day, B. M.; Chen, Y.-C.; Tong, M.-L.; Mansikkamäki, A.; Layfield, R. A., A Dysprosium Metallocene SingleMolecule Magnet Functioning at the Axial Limit. Angew. Chem. Int. Edit. 2017, 56 (38), 11445-11449; (b) Goodwin, C. A. P.; Ortu, F.; Reta, D.; Chilton, N. F.; Mills, D. P., Molecular magnetic hysteresis at 60 kelvin in dysprosocenium. Nature 2017, 548 (7668), 439-442; (c) Randall McClain, K.; Gould, C. A.; Chakarawet, K.; Teat, S. J.; Groshens, T. J.; Long, J. R.; Harvey, B. G., High-temperature magnetic blocking and magnetostructural correlations in a series of dysprosium(iii) metallocenium singlemolecule magnets. Chem. Sci. 2018, 9 (45), 8492-8503.

(9) Guo, F.-S.; Day, B. M.; Chen, Y.-C.; Tong, M.-L.; Mansikkamäki, A.; Layfield, R. A., Magnetic hysteresis up to 80 kelvin in a dysprosium metallocene single-molecule magnet. Science 2018, 362 (6421), 14001403.

(10) (a) Trifonov, A. A.; Shestakov, B.; Long, J.; Lyssenko, K.; Guari, Y.; Larionova, J., An Organoytterbium(III) Complex Exhibiting FieldInduced Single-Ion-Magnet Behavior. Inorg. Chem. 2015, 54 (16), 76677669; (b) Long, J.; Shestakov, B. G.; Liu, D.; Chibotaru, L.; Guari, Y.; Cherkasov, A.; Fukin, G. K.; Trifonov, A.; Larionova, J., An organolanthanide(III) single-molecule magnet with an axial crystal-field: influence of the Raman process over the slow relaxation. Chem. Commun. 2017, 53, 4706-4709.

(11) Selikhov, A. N.; Mahrova, T. V.; Cherkasov, A. V.; Fukin, G. K.; Larionova, J.; Long, J.; Trifonov, A. A., Base-Free Lanthanoidocenes(II) Coordinated by Bulky Pentabenzylcyclopentadienyl Ligands. Organometallics 2015, 34 (10), 1991-1999.

(12) (a) Zhang, X.-Q.; Lin, M.-S.; Hu, B.; Chen, W.-Q.; Zheng, L.-N.; Wu, J.; Chen, Y.-M.; Zhou, F.-Y.; Li, Y.-H.; Li, W., Anionic lanthanide complexes supported by a pyrrole-based tetradentate Schiff base ligand: Synthesis, structures and catalytic activity toward the polymerization of $\varepsilon$ caprolactone. Polyhedron 2012, 33 (1), 273-279; (b) Williams, U. J.; Mahoney, B. D.; DeGregorio, P. T.; Carroll, P. J.; Nakamaru-Ogiso, E.; Kikkawa, J. M.; Schelter, E. J., A comparison of the effects of symmetry and magnetoanisotropy on paramagnetic relaxation in related dysprosium single ion magnets. Chem. Commun. 2012, 48 (45), 5593-5595.

(13) Guo, Y.-N.; Xu, G.-F.; Guo, Y.; Tang, J., Relaxation dynamics of dysprosium(iii) single molecule magnets. Dalton Trans. 2011, 40 (39), 9953-9963.

(14) Meihaus, K. R.; Minasian, S. G.; Lukens, W. W.; Kozimor, S. A.; Shuh, D. K.; Tyliszczak, T.; Long, J. R., Influence of pyrazolate vs Nheterocyclic carbene ligands on the slow magnetic relaxation of homoleptic trischelate lanthanide(III) and uranium(III) complexes. J. Am. Chem. Soc. 2014, 136 (16), 6056-6068.

(15) Shrivastava, K. N., Theory of Spin-Lattice Relaxation. physica status solidi (b) 1983, 117 (2), 437-458.

(16) Chilton, N. F.; Collison, D.; McInnes, E. J. L.; Winpenny, R. E. P.; Soncini, A., An electrostatic model for the determination of magnetic anisotropy in dysprosium complexes. Nat. Commun. 2013, 4, 2551. 


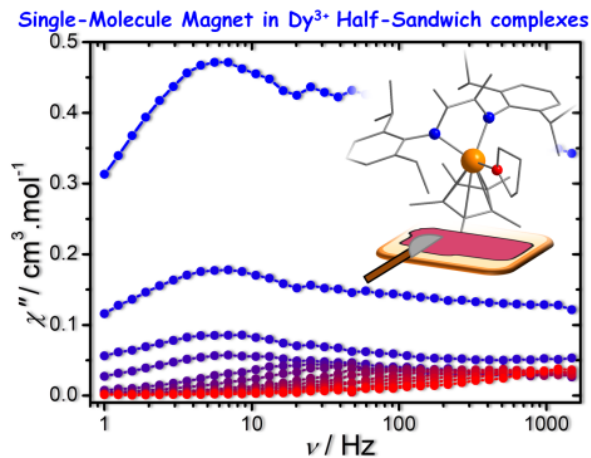

